\title{
Framing, deframing and reframing the Anthropocene
}

\author{
This article belongs to Ambio's 50th Anniversary Collection. Theme: Anthropocene
}

\author{
Noel Castree (1D
}

Received: 7 July 2020/Revised: 25 October 2020/Accepted: 5 November 2020/Published online: 15 March 2021

\begin{abstract}
Publishing in Ambio and elsewhere, geoscientists distributed across several disciplines have both created and substantiated the Anthropocene concept since the turn of the millennium. Epochal and topically encompassing, the concept has served to focus academic and political attention on the extraordinary scale, scope and magnitude of the human impact on the Earth. The concept serves as a metaphorical 'roof' that allows a family of geoscientific terms to reside together harmoniously in the same space. The four Ambio papers evaluated here helped to both build the roof and the family. However, for all their merits, the papers form part of a wider scientific discourse that threatens to colonise the imagination of Earth present and future. A scientific framing of the Anthropocene needs to be deframed and then reframed in terms of what science misses (e.g. diverse social values, needs and wants, which imply alternate courses of possible future action). The papers assessed in this commentary have, albeit unintentionally, helped inspire this de- and reframing in wider social science, the humanities and the arts. Looking ahead, dissonant forms of knowledge and argument about Earth present and future will be key to forging a 'good Anthropocene'. In future, Ambio can help to foster this productive dissonance by loosening its own intellectual parameters while maintaining its high standards of scholarship.
\end{abstract}

Keywords Coupled human and natural systems .

Earth system · Geoscience - Scientism · The Anthropocene

Twenty years ago, 'the Anthropocene' was a neologism coined by Paul Crutzen and Eugene Stoermer. Today, it's a keyword in the lexicon of environmental research and, increasingly, in international environmental policy discourse too. Its ascent to semantic prominence attests to the authority exerted by a variety of geoscientists, even in conditions where deference to 'experts' has declined in many countries. More broadly, it attests to the enduring power of the scientific approach to understanding both people and nature. Unlike previous geoscience concepts that became part of the lingua franca (such as 'acid rain' and the 'ozone hole'), the Anthropocene idea is unusually grand. Of late, it's also become a lightning rod for disagreement about the story of humanity's escalating impacts on the planet. 'The Anthropocene' sits at the heart of a whole family of (not always commensurable) concepts that increasingly frame people's understanding of 'the age of humans'.

To speak about (and for) the Earth System is an extraordinary epistemological privilege. It's also a burden of responsibility to be shouldered (Lovbrand et al. 2015). The four influential Ambio articles discussed here offer a very clear window onto how that privilege and burden have played-out in the wider world of global change research over the last two decades. Their impact, as with most published research, needs to be seen in the context of an 'epistemic ecosystem' comprising thousands of other papers, chapters, reports, conference papers and workshop presentations. The four articles have drawn upon and enlivened this metaphorical ecology of knowledge, creating and connecting new niches over time. Let's consider their specific contributions in turn, and in context. I will then reflect on their double-edged legacy as a solid yet incomplete foundation for future thought and action relating to the Earth.

The first two articles did not mention the Anthropocene. However, as we shall see, they were important precursors to the two influential papers that did. At first reading, 'Resilience and sustainable development: building adaptive capacity in a world of transformations' (Folke 2002) is a rather slight contribution. The text proper is less than 2 
pages ( 4 with images, abstract and 2 boxes). Yet its citation impact is remarkably high, at over 3600 citations in Google Scholar. Upon a closer reading, it's quickly evident why. First, behind it sits a substantial report, prepared for the World Summit on Sustainable Development held in Johannesburg (Folke et al. 2002). Second, the article makes a plenary argument by presenting a number of important propositions and concepts in a coherent, succinct and confident way. The article is not cluttered with caveats and qualifications. Leading scientific researchers authored it: the article's brevity was thus not to be taken as a sign that it could somehow be discounted.

The authors' trick, if I can call it that, was to link then relatively new ideas about ontology to equally new ideas about environmental policy and pitch them as globally (not just regionally or locally) relevant. The idea of coupled socio-ecological systems was presented, along with a challenge to the notions of stasis and progressive change as normal. Conjoined, complex systems can and do alter in abrupt, unpredictable and uncontrollable ways: that was the key ontological message. It follows, the authors argued, that sufficient resilience has to be a key management goal for environments undergoing human forcing. This requires a new management paradigm based on adaptiveness that reduces vulnerability and looks for early-warning signs of unwanted regime shifts. In short, in a world of accelerating change, the best way to arrest run away change is, the authors argued, to shift to a flexible, anticipatory approach geared to promoting socio-economic systems able to withstand constant pressure or sudden shocks. This challenged a century-old management paradigm predicated on reliable knowledge of, and control over, a putatively asocial nature bequeathed by evolution.

Five years later, the paper by Jiangou Liu et al. (2007a) comprehensively summarised what was, by then, emerging as a well-developed alternative to older ideas of a stable nature amenable to rational management (see also Liu et al. [2007b] in Science). Their paper offered a very complete vocabulary to make analytical sense of what, to use their memorable acronym, they called CHANS ('coupled human and natural systems', the title of their paper). While it echoed Folke (2002), the paper went beyond them in nine conceptually crisp pages of text. Its integrative framework discussed CHANS in terms of complexity, feedbacks, direct effects, indirect effects, emergent properties, resilience, vulnerability and thresholds. It then tracked these key organisational features through to spatial couplings and ever larger and long-lived temporal couplings-providing a fairly granular toolkit of terms to do so. The latter part of the paper went on to consider how the realities of CHANS necessarily change the realities of environmental management, at all scales. CHANS, the authors argued, call for new modes of research, new training for scientists and new training for aspiring environmental managers who must somehow manage the potentially unmanageable. Rising to the challenge, Liu et al. acknowledged, was both necessary and yet formidably difficult. Their paper carried authority by virtue of its impressive author team (which included climate scientist Stephen Schneider, political economist Elinor Ostrom \& ecologist Jane Lubchenco) and exhaustive referencing (to over 160 bibliographic items). It signalled a determination to avoid 'boxing' environmental challenges in terms of 'climate', 'biodiversity', 'water resources' and so on.

The two papers discussed above were among several of this ilk published around the turn of the millennium. Often, the same authors (e.g. ecologist Stephen Carpenter) wrote variations on the principal themes for different journals, thereby disseminating the new thinking widely across the geosciences and, to a lesser degree, environmental social science. Inspired by research in ecology, they broadened out from biological systems to convey an important new message about understanding and governing a socio-ecological world that was likely to be unruly. Without a tapestry of contributions like these, the papers by Steffen et al. $(2007,2011)$ could not, arguably, have been written in the ways they were-even though these papers contained very important messages not found in Folke et al. or Liu et al. So, what were these messages and why were they important?

'The Anthropocene: are humans now overwhelming the great forces of nature?' is a modern classic (over 3100 citations in Google Scholar, and rising). Though short (six and three quarter pages of text), it was among the first papers to declare the Anthropocene a new reality and to examine its causes (in an historical context) and implications. Building on the important research by the International Geosphere-Biosphere Program (IGBP), and a joint project with the International Human Dimensions Program (the IHOPE project: integrated history of people on Earth, which is ongoing within Future Earth), the paper did a number of things. It replayed the theme of CHANS but now in terms of the whole Earth System (still a relatively new concept 14 years ago); it replayed the theme of threshold crossing, but now framed provocatively as the end of a natural epoch; and it replayed the theme of biophysical surprises and unruliness but in the evocative notion of human's 'overwhelming' a relatively stable Holocene system state. The paper periodised the human impact at a planetary scale in a heuristically appealing 'stages' model and presented IGBP's arresting 'Great Acceleration' diagrams (now quite familiar to students of humanity's effects on the planet). Looking ahead, the paper outlined the main options (business as usual, mitigation and geoengineering counter-measures) and floated the notion of whole Earth stewardship. While 
hardly new, the latter idea was a reminder of the failure of nations to make real progress since the Bruntland Report of 1987. Though it was a simple paper, relative to the complexities of its topic, this was part of the appeal. The authors (two world leading geoscientists and a respected environmental historian) threw a rope around a set of important issues and tied them together very neatly.

The Steffen et al. paper helped to launch the Anthropocene concept to prominence within and beyond geoscience (the citations to the term take-off from 2007 onwards). But the later paper by Steffen, Jan Zalasiewicz and fourteen other esteemed authors (Steffen et al. 2011) is arguably, with hindsight, of greater significance (this notwithstanding fewer, if still impressive, citations at around 1400 in Google Scholar at the time of writing). As a longer article, it was the result of a Nobel Laureate Symposium (held in May 2011). As with Steffen et al. (2007), it placed ideas from Folke (2002) and Liu et al. (2007a) in an Earth System framework. But it also introduced the notion of Earth System goods and services in order to sharpen the point that the 'Holocene envelope' is precious and in need of preservation. It invoked the terms 'crisis' and 'civilisational collapse', while flagging social equity as a key issue. There are memorable lines in the article, such of the oft-quoted "We are the first generation with the knowledge ..., the power and the responsibility to change our relationship with the planet" (p. ?). The, at the time new, notion of planetary boundaries was also used to set parameters around the exercise of this power and responsibility (Johan Rockstrom was one of the paper's authors). Relatedly, the notions of bifurcation points and tipping elements were introduced to warn of the dangers of entering planetary terra incognita (Marten Scheffer was one of the co-authors). Additionally, having the head of the new Anthropocene Working Group as a co-author signalled that some geologists were taking seriously the otherwise 'incredible' idea that humans were pushing the Earth System into a new regime state-something only previously achieved by natural processes. Overall, the paper issued a sober warning and flagged the necessity of pro-active, coordinated management of human activities on the Earth. A stellar group of geoscientists lent their name to it. Importantly, they did so in the lead-up to the second United Nations Earth Summit (Rio + 20), as part of a special issue of Ambio designed to sound the alarm about humanity's treatment of the planet.

The four papers discussed above helped to shift the discourse, in both academia and the wider world, about people and the Earth. They were important parts of patient, persistent work undertaken by thousands of researchers in fields like climatology, ecology, oceanography and economics. This work has involved numerous geoscientists, and not a few environment social scientists, stepping off the usual academic tramlines. Steffen, Rockstrom, Crutzen and others have variously used global environmental assessments, attendance at high-level government meetings, the writing of declarations, news media releases and other mechanisms to reframe collective understanding of global environmental change. The Anthropocene concept, given empirical substance through countless scientific articles since around 2010, has been at the heart of this understanding. No longer a buzzword, it's become a keyword (at least in academia). Encompassing in meaning, it has allowed a family of geoscience ideas to be gathered together under one semantic roof. In research terms, it has helped promote the move towards solutions-focussed transdisciplinary inquiry, exemplified by Future Earth (https://futureearth.org/). Politically, it has (especially through various United Nations fora) heightened our awareness of the many failings of current protocols and agreements designed to reduce humanity's global environmental footprint. More positively, it has accented the need for integrated action, as aspired to by the Sustainable Development Goals agreed in 2015.

As Ambio enjoys its 50th birthday, it is evident that the scientific representation of the Anthropocene is both necessary and yet quite problematic. That science has shown that anthropogenic climate change-perhaps the iconic environmental problem of our time-is but one part of a larger, more worrying problem (what many could label a global crisis, whose worst effects our descendants will bear the brunt of). The authority enjoyed by science in general has allowed Anthropocene science to be taken seriously beyond universities, even if social deference to expert insight is much less than it once was. The science, to echo Klein's (2015) well-known refrain, should 'change everything' because it reveals that everything is changing, both around us and also because of us. However, awareness of the high-stakes scientific messages is not translating into significant inter-governmental action regarding mitigation and adaptation. This 'knowledge-action gap' is long-standing and is complicated in its causes. Some attribute the gap to the unavoidable uncertainty built-into scientific pronouncements about the Earth System. This uncertainty can weaken policy makers' resolve to undertake expensive and politically contentious socio-technical change (such as a Green New Deal and de-carbonisation of energy and transportation). The uncertainly invites calls for 'more science' and for challenges (made in good or bad faith) to the quality of the current science by non-scientists. Others note that policymakers' decisions are affected by a myriad of key drivers, scientific advice being but one-and rarely the decisive one (cf. the covid-19 pandemic, where science advice is playing a very prominent role in determining government policy in many countries at present).

However, even if these other drivers did not exist, it turns out that the science is not, in fact, an adequate basis 
for translation from knowledge to action. Instead, we need a different language to motivate and guide planetary stewardship. Here, we have to acknowledge the limitations of thinking in terms of planetary boundaries, Earth System regime shifts, complex and ramified feedbacks, and so on. One obvious limit, noted by many commentators, is the implicit invitation to some people to engineer the planet's environment-for instance, through stratospheric aerosol injection as a thermostatic 'last resort' (or Plan B). This is but one (potentially risky) 'ought' implied by the 'is' of epochal planetary change. It should not be contemplated without full consideration of several potential Plans A, most with a societal (not environmental) focus. Another limitation is the lack of sufficient explanatory detail (exemplified in the two Anthropocene papers discussed above) about the nature of 'the human enterprise' driving us out of the Holocene. Depending on how one characterises that enterprise (is it about market failure, poorly regulated capital accumulation, anthropocentric materialism, a masculine will to dominance..?), the 'solutions' to avoiding a 'bad Anthropocene' look very different indeed. As Dalby (2015) notes, there is more than one way to engender a 'good' Anthropocene, not just because several practical options are available but also because these options' suitability must be evaluated according to contestable value judgements about what counts as 'good'. These judgements speak to the perennial and profound existential question 'how should we live?'. Earth System change does not objectively mandate 'right' answers to this question.

These, and many other limitations, have fuelled a lively effort to prevent inadvertent science imperialism in the epistemic framing of the Anthropocene. The effort has been led by critical social scientists and humanists (CSSH) across a wide spectrum of disciplines, some of them former geoscientists (notably Mike Hulme, at Cambridge University). These analysts have accepted the seriousness of the scientists' insights, but they seek to change the narrative about causes and responses. The way they depict the 'everything' being changed by humans-and to be changed in future-varies hugely (see Bonneiul and Fressoz 2017). Far from being relativists, their insights reflect real and significant differences in cognitive and normative perspectives about the human condition, existing both in universities and the wider world. These differences make a difference to the sort of scientific evidence, and technologies, which will be deemed most relevant and legitimate to making the planet more liveable. As yet, the CSSH perspectives have not garnered the wider attention enjoyed by authors of publications like the four highlighted here (see Castree 2017). That needs to change-for instance, through some of the Future Earth projects and networks, and some initiatives within the UNESCO MOST (Management of Social Transformations) programme (https://en.unesco.org/ themes/social-transformations/most). It will be challenging, though. For instance, introducing normative expertise (e.g. moral philosophy) into Earth System analysis could readily lead to the de-legitimisation of the knowledge and arguments being presented-especially in light of recent 'post-truth' and populist practices in politics and the media.

I have elsewhere suggested that a revised format for global environmental assessments can provide a wellstructured, and well-justified, mechanism for bringing geoscience, social science, the humanities and even the arts into the high-level 'conversation of humankind' that need urgently now to occur (Castree et al. 2021). This conversation will be deeply political and requires protection from the short termism and hurly burly of every day political discourse in the news media, parliaments and elsewhere. But we must remember that the insights of geoscience about the Earth System only make practical sense when set within a political horizon. And we should remember too that political reasoning is not merely or only the realm of 'preference', 'opinion' or 'interests': at its best, it involves the sort of textured arguments, supported by evidence, that the CSSH (among others) is dedicated to providing. Good-quality, and socially legitimate, decision-making requires such arguments. The future of the planet is too serious a matter to be predicated on political sound bites, populist slogans and other maladies afflicting public reason during the 2020s.

As we look ahead, there is a challenge for Ambio and interdisciplinary journals operating in the same intellectual space. Can they move away from a largely scientific framing of people and planet without, of course, diminishing the value or quality of the science? Can they get beyond and assumption that interdisciplinarity is about different experts collaborating so as to reveal a single (total) picture of the world? We will know the answer in another 50 years when the centenary volume is published, but hopefully much sooner than that. In its five decades so far, Ambio has done a great deal to trigger the conversation about people and planet we desperately need to have across our diverse and divided globe. The more democratic that conversation is, the better chance humanity has of achieving a 'good Anthropocene', once we determine openly and honestly what the 'good' is we should now be aiming for.

Acknowledgements I am grateful to the editors of Ambio for the invitation to write this commentary. I owe particular thanks to Wiebren Boonstra and two anonymous referees for very helpful feedback on the first draft.

\section{REFERENCES}

Bonneiul, C., and J.-B. Fressoz. 2017. The shock of the Anthropocene. London: Verso. 
Castree, N. 2017. Speaking for the 'people disciplines': Global change science and its human dimensions. The Anthropocene Review 4: 160-182.

Castree, N., R. Bellamy, and S. Osaka. 2021. The future of global environmental assessments: a case for fundamental change. Anthropocene Review. https://doi.org/10.1177/205301962097 1664.

Dalby, S. 2015. Framing the Anthropocene: The good, the bad and the ugly. Anthropocene Review 3: 33-51.

Folke, C. 2002. Resilience and sustainable development: Building adaptive capacity in a world of transformations. Ambio 31: 437-440. https://doi.org/10.1579/0044-7447-31.5.437.

Folke, C., S. Carpenter, T. Elmqvist, L. Gunderson, C.S. Holling, B. Walker, J. Bengtsson, F. Berkes, et al. 2002. Resilience and sustainable development. Stockholm: The Swedish Environment Advisory Council.

Klein, N. 2015. This changes everything. New York: Simon \& Schuster.

Lovrand, E., S.S. Beck, J. Chilvers, T. Forsyth, J. Hedren, M. Hulme, R. Lidskog, E. Vasileiadou, et al. 2015. Who speaks for the future of the earth? Global Environmental Change 32: 211-218.

Liu, J., T. Dietz, S.R. Carpenter, C. Folke, M. Alberti, C.L. Redman, S.H. Schneider, E. Ostrom, et al. 2007a. Coupled human and natural systems. Ambio 36: 638-649. https://doi.org/10.1579/ 0044-7447(2007)36\%5b639:chans\%5d2.0.co;2.

Liu, J., T. Dietz, S.R. Carpenter, M. Alberti, M. Folke, E. Moran, A.N. Pell, P. Deadman, et al. 2007b. Complexity of coupled human and natural systems. Science 317: 1513-1516.
Steffen, W., P. Crutzen, and J.R. McNeill. 2007. The Anthropocene: Are humans now over-whelming the great forces of nature? Ambio 36: 614-620. https://doi.org/10.1579/00447447(2007)36\%5b614:taahno\%5d2.0.co;2.

Steffen, W., A. Persson, L. Deutsch, J. Zalasiewicz, M. Williams, K Richardson, C. Crumley, P. Crutzen, et al. 2011. The Anthropocene: From global change to planetary stewardship. Ambio 40: 739-761. https://doi.org/10.1007/s13280-011-0185-x.

Publisher's Note Springer Nature remains neutral with regard to jurisdictional claims in published maps and institutional affiliations.

\section{AUTHOR BIOGRAPHY}

Noel Castree $(\square)$ is a Professor of Environment and Society at UTS in Sydney, and a member of the Geography Department at Manchester University, England. His research and teaching explores the links between matter and meaning, fact and value, is and ought. He is the author of Making Sense of Nature (2014, Routledge) and edits the journal Progress in Human Geography (Sage). Most recently, he has advocated for an expanded notion of 'environmental assessment' in the pages of Anthropocene Review, a notion that encompasses geoscience, environmental social science and the environmental humanities.

Address: University of Technology, Sydney (UTS), Ultimo, Australia e-mail: noel.castree@uts.edu.au 